\title{
A PROTEÇÃO ESTATAL DE PESSOAS TRAFICADAS E CONTRABANDEADAS À LUZ DA SEGURANÇA HUMANA'
}

\author{
STATE PROTECTION OF PEOPLE TRAFFICKED AND SMUGGLED IN THE \\ LIGHT OF HUMAN SECURITY
}

DOI: $10.5380 / \operatorname{cg} . v 10 i 1.78099$

Joyce Kelly²

\begin{abstract}
Resumo
O tráfico e o contrabando de pessoas são problemas globais que atingem várias dimensões da vida social. No cenário internacional, após a adoção da Convenção de Palermo em 2000, o tráfico e o contrabando de pessoas passaram a ser vistos pela comunidade internacional como problemas que fazem parte de um processo ligado essencialmente ao crime organizado internacional. Consequentemente, muitas vezes, devido à abordagem ser focada na segurança estatal, é dado mais ênfase à repreensão, deixando a proteção das vítimas em segundo plano. O presente artigo propõe uma discussão sobre o problema do tráfico e do contrabando pela ótica do indivíduo que é explorado. Para tanto, será utilizado o conceito de segurança humana, que fornece um quadro multidimensional que visa ampliar as ameaças a serem minimizadas pelo compromisso estatal com a dignidade e a liberdade do indivíduo. Metodologicamente, foi empregada uma revisão de literatura com o objetivo de identificar a discussão sobre tráfico dentro das Relações Internacionais. Além da literatura, exploraram-se documentos com o objetivo de apresentar evidências empíricas.
\end{abstract}

Palavras-Chave: Tráfico. Contrabando. Migrantes. Estado. Segurança Humana.

\begin{abstract}
Human trafficking and smuggling are global problems that affect various dimensions of social life. On the international stage, after the adoption of the Palermo Convention in 2000, human trafficking and smuggling came to be seen by the international community as a problem that is part of a process essentially linked to international organized crime. As a result, often because the approach is focused on state security, more emphasis is placed on reprimand, leaving victim protection in the background. This article proposes a discussion on the problem of trafficking and smuggling from the perspective of the individual who is exploited. To this end, the concept of human security will be used, which provides a multidimensional framework that aims to expand the threats to be minimized by the state's commitment to the dignity and freedom of the individual. Methodologically, a literature review was used in order to identify the discussion on trafficking within International Relations. In addition to the literature, documents were explored in order to present empirical evidence.
\end{abstract}

Keywords: Trafficking. Smuggling. Migrants. State. Human Security.

\footnotetext{
${ }^{1}$ Este artigo está licenciado sob a Licença Creative Commons Attribution (CC BY 4.0), sendo permitido o compartilhamento com reconhecimento da autoria e publicação inicial nesta revista.

${ }_{2}^{2}$ Mestra em Relações Internacionais pela Universidade Estadual da Paraíba (2019) e Bacharela em Relações Internacionais pela mesma instituição (2016). Pesquisadora do Grupo de Estudos em Política, Relações Internacionais e Religião (GEPRIR/UEPB). E-mail: joycce kelly@hotmail.com. ORCID: https://orcid.org/o000-0002-0698-8342.
} 


\section{INTRODUÇÃO}

Várias são as razões para as pessoas se deslocarem e vários também são os mecanismos utilizados nesses deslocamentos. O tráfico de pessoas e o contrabando de migrantes vêm sendo incorporados a esses mecanismos de deslocamento como uma ferramenta criminosa que se tem tornado um grande problema de segurança internacional (SANTOS, 2015). De acordo com Venson e Pedro (2013), o tráfico de pessoas é um conceito jurídico que surgiu durante o século XIX, mas que reapareceu com mais força no final do século XX, fruto da discussão sobre a necessidade de proteção das fronteiras transnacionais (VENSON; PEDRO, 2013, p.62).

Os crimes transnacionais envolvem delitos que ultrapassam as fronteiras internacionais ou que afetam os interesses de mais de um Estado. Eles podem ser divididos em "crimes domésticos", que são crimes que ocorrem dentro de uma única fronteira nacional, e "crimes internacionais", que são crimes reconhecidos pelo direito internacional e que vão contra a comunidade internacional. Os crimes internacionais são todos os crimes que ameaçam a ordem, a segurança e a vida dos seres humanos no cenário internacional. No ano 2000, foi estabelecida pela Assembleia Geral da ONU a Convenção contra o Crime Organizado Transnacional. Essa Convenção internacional é complementada por três Protocolos: um relativo ao tráfico de armas de fogo, outro sobre o tráfico de pessoas e o terceiro sobre o contrabando de migrantes (ANDERSON, 2014). Foi então, a partir da adoção da Convenção, que o tráfico de pessoas passou a ser considerado um problema de segurança internacional, bem como uma ameaça ao Estado. 3

De acordo com a definição, o tráfico de seres humanos, ou de pessoas, envolve um processo que inclui essencialmente o recrutamento, o transporte e a exploração. O contrabando de migrantes envolve a entrada ilegal de uma pessoa em um Estado do qual essa pessoa não é nacional ou residente, facilitada por agentes para ganho financeiro (ONU, 2000). O tráfico é visto pelos Estados como tendo uma ligação com o crime organizado, que se configura como um problema de segurança internacional, dando ênfase à repressão e não à proteção das vítimas (DIAS, 2015). Segundo Sales e Alencar (2008), tratar as pessoas traficadas simplesmente como imigrantes ilegais ${ }^{4}$, deportando-as aos seus países de origem sem dispensar o tratamento adequado às vítimas de exploração, é um erro grave, pois tanto o tráfico como o contrabando constituem uma grave violação dos direitos humanos (SALES; ALENCAR, 2008, p.30).

Diante desse problema, existe um conceito dentro dos estudos de segurança que é composto por uma estrutura a qual pressupõe que, com a ampliação das ameaças, os Estados têm a obrigação

\footnotetext{
${ }^{3} \mathrm{~A}$ ONU identificou várias categorias diferentes de crimes transnacionais: tráfico de drogas, tráfico de pessoas, tráfico de órgãos, tráfico de bens culturais, falsificação, lavagem de dinheiro, atividades terroristas, roubo de propriedade intelectual, tráfico ilícito de armas, sequestro de aeronaves, pirataria marítima, sequestro de terras, fraude em seguros, crime ambiental, falência fraudulenta, infiltração de negócios legais, corrupção e suborno de funcionários públicos e outros crimes cometidos por grupos do crime organizado (UNODC, 2002, p. 4).

${ }^{4}$ Imigrante irregular/ilegal/clandestino ou indocumentado são aqueles que, devido ao ingresso sem os documentos exigidos pelo país de trânsito ou de acolhimento infringem às normas admitidas pelo país (LARA, 2008).
} 
de manter a segurança das suas fronteiras nacionais, ao passo que sejam mantidas a segurança dos indivíduos que vivem nessas fronteiras. A segurança humana, como é conhecida, estabelece que os Estados sejam responsáveis por proteger os seus cidadãos de conflitos externos e danos internos, e também tenham o dever de fazer com que os cidadãos desfrutem de uma vasta gama de direitos e sejam capazes de viver suas vidas com um senso de dignidade e ausência de medo (CLARK, 2003, p. 248).

Para tanto, esse artigo visa responder a seguinte questão: de que forma o Estado pode aplicar o conceito de segurança humana para facilitar o enfrentamento ao tráfico e ao contrabando de pessoas? O objetivo do artigo é, portanto, discutir como esses problemas podem ser minimizados por meio de uma mudança na percepção dos Estados, ou seja, de ver esses problemas pela ótica da segurança humana, para além da ótica da segurança estatal internacional. A proposta fundamental é trazer um "novo olhar" para o tráfico a partir do conceito de segurança humana. A hipótese levantada é que os pressupostos da segurança humana visam proteger as populações vulneráveis do risco de serem traficados em seus países de origem, de trânsito e destino. Atuando, assim, no cerne do problema.

Metodologicamente, foi empregada uma revisão de literatura com o objetivo de identificar a discussão sobre tráfico dentro das Relações Internacionais. Além da literatura, exploraram-se documentos com o objetivo de apresentar evidências empíricas. A estrutura do artigo está composta por três seções. A primeira trará a discussão sobre o tráfico e o contrabando de pessoas, sua definição e seu tratamento no cenário internacional. A segunda seção abordará os principais problemas relacionados ao tráfico e ao contrabando de pessoas, com destaque para o caráter exploratório das vítimas. A terceira seção abordará a teoria da segurança humana e seus principais pressupostos. E, por fim, a quarta seção discutirá como a segurança humana pode servir como um meio a ser utilizado pelos Estados para minimizar o problema do tráfico e contrabando de pessoas.

\section{TRÁFICO DE PESSOAS E CONTRABANDO DE MIGRANTES}

Apesar de o tráfico de pessoas e do contrabando de migrantes terem ganhado destaque com a globalização, tanto o crime organizado internacional como o próprio tráfico já eram fenômenos que ocorriam mesmo durante a Guerra Fria. De acordo com Costa (2012), o que ocorreu com a globalização foi uma reemergência e uma profissionalização do problema, que envolve uma vasta gama de fatores. Assim, a partir do momento em que o ser humano passou a ser tratado como mercadoria, ou, como o autor coloca, "um recurso, a ser contabilizado de forma fria e matemática a ser gerenciado como qualquer produto ou coisa”, o comércio de seres humanos passou a existir (COSTA, 2012, p.12). Segundo Munro (2006) citado por Baptista (2021), a globalização dificulta a distinção entre "vítima, agente do tráfico, redes, cliente e o Estado". Para o autor, os diversos fatores 
relacionados ao tráfico que foram gerados pela globalização, como o aumento da desigualdade socioeconômica, instabilidade econômica e a busca das pessoas por melhores condições de vida, confundem a análise coordenada dos Estados com a comunidade internacional (MUNRO, 2006 apud BAPTISTA, 2021, p.6).

Nesse sentido, por ser um problema global e que atinge várias dimensões da vida social, há algumas divergências dos atores quanto ao tratamento dado às pessoas traficadas, bem como quanto à definição. De acordo com Bhabha e Zard (2006), as pessoas traficadas são vistas de três formas diferentes. A primeira está ligada à visão do migrante como uma vítima incapaz de defender-se e que, portanto, necessita de proteção adequada. Essa perspectiva promove a criação de políticas com base nos direitos humanos e nos direitos dos refugiados. A segunda visão é uma variante da primeira e refere-se à percepção do migrante como uma pessoa que está em busca de uma vida melhor, trabalhando de forma a contribuir tanto para o país de destino quanto para o país de origem. Nesse caso, é dada ênfase às políticas de anistia e regularidade do status do migrante. E, por fim, a terceira visão, que é considerada a percepção “dominante", vê o migrante como uma ameaça para a segurança do Estado, considerando-o como um criminoso. Esta visão nutre e fortalece as respostas às migrações baseadas no direito penal, que criminaliza a facilitação e a transição de pessoas pelo controle das fronteiras (BHABHA; ZARD, 2006, p.6).

Por muitos anos foi difícil encontrar um consenso quanto à definição do que seria o tráfico de pessoas. Um dos primeiros instrumentos adotados pelos Estados sobre o assunto data de 1904, após a adoção de um tratado que se referia ao "tráfico de escravas brancas”. Em 1949, a recém-criada Organização das Nações Unidas adaptou a Convenção para a Repressão do Tráfico de Pessoas e Exploração da prostituição, instrumento este juridicamente vinculativo que punia as pessoas que castigavam outras para fins exploratórios e de prostituição sem consentimento delas. Entretanto, esse instrumento não teve muita aceitação pelos Estados e logo foi abandonado (ANDERSON, 2014, p.356). Foi somente no começo do século XX, no ano 2000, que foi adotada pela Assembleia Geral da ONU na cidade de Palermo, Itália, a Convenção contra o Crime Organizado Transnacional, complementada por mais três Protocolos: um relativo ao tráfico de armas de fogo, outro sobre o tráfico de pessoas e outro sobre o contrabando de migrantes. (CAMPOS, 2007, p.38; ANDERSON, 2014; DIAS, 2015). Foi a partir da adoção da Convenção que o tráfico de pessoas passou a ser considerado um problema de segurança internacional, pensado essencialmente "em um contexto de preocupações com o controle de fronteiras nacionais, visto que o intuito é combater o crime organizado" (VENSON; PEDRO, 2013, p.75). Dessa forma, de acordo com o Protocolo, tráfico de pessoas se refere ao:

Recrutamento, o transporte, a transferência, o alojamento ou o acolhimento de pessoas, recorrendo à ameaça ou uso da força ou a outras formas de coação, ao rapto, à fraude, ao engano, ao abuso de autoridade ou à situação de vulnerabilidade ou à entrega ou aceitação de pagamentos ou benefícios para obter o consentimento de 
uma pessoa que tenha autoridade sobre outra para fins de exploração (BRASIL, 2006).

A definição estabelece, deste modo, o processo que compõe o tráfico de pessoas, que é essencialmente: o recrutamento, o transporte e a exploração. Sobre o recrutamento, um dos pontos que tem gerado discussão na definição é quanto ao consentimento da vítima. O que acontece no tráfico é que as organizações criminosas utilizam de certo grau de "colaboração da vítima”, por meio do engano, para executar o ato criminoso. Entretanto, para o Protocolo do tráfico, o consentimento da vítima é irrelevante para caracterizar o ato como tráfico, na medida em que o criminoso utiliza de um dos meios ilícitos apontados na definição (ameaça ou uso da força ou a outras formas de coação, ao rapto, à fraude, ao engano, ao abuso de autoridade) ou se aproveita da vulnerabilidade da vítima (SCACCHETTI, 2011, p.26).

Com relação ao transporte, tanto pode acontecer dentro (tráfico interno) quanto fora das fronteiras nacionais (tráfico internacional). A esse respeito é fundamental diferenciar o tráfico de pessoas do contrabando de migrantes. Segundo o United Nations Office on Drugs and Crimes (UNODC), o contrabando de pessoas é sempre transnacional e é considerado "um crime que envolve a obtenção de benefício financeiro ou material pela entrada ilegal de uma pessoa em um país no qual essa pessoa não seja natural ou residente". No caso do contrabando, "mesmo em condições perigosas e degradantes, a pessoa contrabandeada tem o conhecimento e o consentimento sobre o ato criminoso". No geral, o Protocolo do contrabando estabelece como dever dos Estados a criminalização da passagem irregular das fronteiras, na medida em que a passagem ilegal torna $o$ migrante irregular, muitas vezes considerado um criminoso (UNODC, 2017).

Ainda relacionado ao transporte, as autoridades têm dificuldades de combater os contrabandistas, pois, de maneira geral, para as pessoas que utilizam esses serviços, o contrabandista não é visto como criminoso, mas sim como "facilitador". Outro ponto, é que diversas vezes "o próprio contrabandista se passa por "imigrante irregular" junto ao grupo que estava tentando contrabandear", dessa forma, caso seja capturado ele será apenas repatriado para seu país de origem. Por isso, essa atividade é considerada de alta demanda e pouco risco, tornando-se uma prática bastante atrativa (COSTA, 2012, p.16). Muitas vezes é a confusão com relação à expressão "tráfico de seres humanos" e "contrabando de migrantes" que tem decorrido o tratamento das vítimas de tráfico como criminosas, afastando-as da proteção que lhe é devida enquanto vítimas. Por isso, é importante identificar as diferenças fundamentais entre essas duas categorias que essencialmente podem ser vistas no consentimento, na consciência do ato ilícito, na fonte de lucro, no caráter nacional e/ou transnacional e no fator exploratório (PINTO, 2017).

A última parte do processo que compõe a definição de tráfico é, portanto, a exploração, que, segundo Campos (2007), é o aspecto que verdadeiramente distingue o tráfico de outras formas de violações dos direitos humanos que, algumas vezes, vinculam-se às migrações irregulares. $\mathrm{O}$ caráter 
exploratório que acontece no tráfico de pessoas está ligado, sobretudo, a tirar vantagem da vítima com o objetivo de obter algum tipo de ganho econômico da mesma (CAMPOS, 2007, p.38).

Assim, a partir do processo que compõe a definição, pode-se perceber que a prioridade adotada pela Convenção de Palermo é o combate ao crime organizado transnacional, focado no controle das fronteiras. Segundo Pires e Galvão (2010), "o silêncio dos dois protocolos em incluir proteções obrigatórias aos migrantes" demonstra esse fato, na medida em que as pessoas que tentam atravessar as fronteiras ilegalmente, comumente, são consideradas criminosas e não são dignas de assistência (PIRES; GALVÃO, 2010, p.479). Baptista (2021, p.4) afirma que, em termos de objeto, a definição de tráfico de pessoas exagera "no foco na justiça criminal, essencialmente mais reativa do que preventiva, cujo foco é a coerção e prisão em contexto transnacional”. Esse fato ignora de certa forma o caráter de vulnerabilidade que essas pessoas se encontram e a exploração que elas sofrem (BAPTISTA, 2021). Essas questões serão discutidas a seguir.

\section{EXPLORAÇÃO E VULNERABILIDADE}

O caráter exploratório que compõe a definição do tráfico e do contrabando de pessoas deixa implícito que a exploração é uma violação dos direitos humanos conformados pela comunidade internacional. O que se conclui da definição de exploração no Protocolo de Palermo é que, nas palavras de Rijken (2009), "é uma forma de abuso de natureza excessiva, como resultado da seriedade de manipulação física ou emocional (ameaças e violência) ou como resultado de múltiplas restrições impostas à vítima”. São esses excessos que configuram a violação dos direitos humanos, no sentido da privação dos direitos elementares da vida humana, como a liberdade de escolha e de movimento e a independência (RIJKEN, 2009). A exploração que compõe o tráfico e/ou contrabando de pessoas inclui "prostituição de outrem ou outras formas de exploração sexual, o trabalho ou serviços forçados, escravatura ou práticas similares à escravatura, a servidão ou a remoção de órgãos" (BRASIL, 2006).

O primeiro tipo de exploração é, pois, a prostituição ou a exploração sexual. A exploração para fins sexuais tem sido um dos problemas que mais tem crescido mundialmente e tem gerado uma grande preocupação para a comunidade internacional. Geralmente, o fluxo do tráfico ligado à exploração sexual ocorre dos países em desenvolvimento para os países desenvolvidos, onde a demanda é mais alta devido às áreas de turismo sexual (SALES; ALENCAR, 2004).5 No Brasil, por exemplo, nas regiões Norte e Nordeste são encontrados os maiores índices de rotas de tráfico de mulheres e adolescentes e crianças, comparados com as regiões Sul e Sudeste, devido, sobretudo, à

\footnotetext{
${ }^{5} \mathrm{O}$ turismo sexual geralmente é visto como uma prática que é realizada por homens ricos dos países desenvolvidos que viajam para os países em desenvolvimento "com o objetivo de se relacionar sexualmente com mulheres nativas, mediante pagamento em dinheiro ou presentes". Contudo, essa prática tem se expandido na medida em que mulheres também têm viajado com esse objetivo, alimentando assim o "turismo do sexo" (SALES; ALENCAR, 2204, p.39).
} 
falta de oportunidade, falta de políticas públicas, pobreza, miséria e à seca. Este fato confirma a correlação entre as desigualdades sociais e a saída de pessoas das regiões menos desenvolvidas para tentar a vida em regiões mais desenvolvidas (PACÍFICO; LEITE; SOUTINHO, 2010). Vale destacar que grande parte das vítimas desse tipo de exploração são mulheres.

De acordo com o último relatório produzido pelo UNODC, em 2018, sete em cada dez vítimas de tráfico eram mulheres, sendo cinco mulheres adultas e duas meninas. Como dito, a maioria das mulheres é traficada para fins de exploração sexual, mas também existem relatos de tráfico para fins de casamento forçado e alguns casos de mulheres grávidas ou meninas que são traficadas para fins ilegais de adoção (UNODC, 2020). Kempadoo (2005) argumenta que esse fato tem gerado um amplo debate entre as feministas que questionam o tema da migração ligado à prostituição. Esse debate tem sido construído sobre duas vertentes principais. A primeira tem origem ocidental e parte de uma análise radical das relações sociais. Essa vertente vê a prostituição como uma intensa opressão patriarcal e considera que a "indústria global do sexo" constrange as mulheres à prostituição, mantendo-as como escravas sexuais e violando seus direitos e integridade corporal (KEMPADOO, 2005).

A segunda vertente é basicamente uma crítica da primeira, que tem o tráfico "como discurso e como prática que emerge das interseções de relações de poder estatais, capitalistas, patriarcais e radicalizadas”. O patriarcado ou a dominação do homem sobre a mulher é visto como uma das relações de dominação, e não a única, considerando também o racismo, o imperialismo e as desigualdades como condicionantes. Em geral, essa abordagem pressupõe que o "trabalho do sexo" atende a uma demanda das próprias mulheres que, de forma consciente e voluntária, buscam melhorar suas vidas. Assim, a prostituição em si não é uma violência, mas sim o "terror que cercam esse trabalho num setor informal ou subterrâneo". De maneira geral, essas duas vertentes de debates entre as feministas são importantes, pois dão ênfase à questão de exploração de gênero no cenário internacional e na academia (KEMPADOO, 2005, p.65).

Outro tipo de exploração é a relacionada ao trabalho forçado. O processo que compõe essa modalidade de tráfico ou temas correlatos à escravidão pela norma internacional é feita desde o século XIX. Foi em 1930 que a Organização do Trabalho (OIT) elaborou o conceito de trabalho forçado. Segundo este, trabalho forçado ou obrigatório é "todo trabalho ou serviço exigido de uma pessoa sob a ameaça de sanção e para o qual ela não tiver se oferecido espontaneamente" (COSTA, 2012, p.24). Segundo o relatório da UNODC, as vítimas traficadas para fins de trabalho forçado não necessariamente atuam em mercados ilícitos ou secretos, mas em empresas devidamente registradas em setores que fazem parte do cotidiano da sociedade como a produção de alimentos, construção civil ou fabricação de roupas. Em 2018, o trabalho forçado contabilizou cerca de $38 \%$ do total de casos de tráficos detectados no mundo. As regiões da África Subsaariana, Sul da Ásia e Europa Oriental e Ásia Central têm os maiores índices desse tipo de tráfico no cenário internacional (UNODC, 2020). 
Do ponto de vista conceitual, conforme apontam Vasconcelos e Bolson (2008), o trabalho forçado estabelece o mínimo necessário, que é a eliminação de qualquer forma de trabalho forçado ou obrigatório. Assim, já nos anos 2000, o conceito foi ampliado, deixando claro que somente baixos salários ou más condições de trabalho não podem definir o trabalho forçado, mas sim a restrição da liberdade do trabalhador, estabelecido como uma grave violação dos direitos humanos. Salientada a ameaça e o caráter involuntário do trabalho, novamente vale a problematização da questão do consentimento, pois, muitas vezes, o trabalho começa livre e torna-se forçado posteriormente, "por meio de coerções legais, físicas ou psicológicas que impedem o rompimento da relação de trabalho" (VASCONCELOS; BOLZON, 2008, p.72).

No contexto da migração, o trabalho forçado aparece de diferentes formas: ou a convite de algum conhecido no local de destino ou por conta própria. A migração para outro local em busca de melhores condições de vida somente vai- se configurar tráfico quando algumas das etapas que a definição aborda forem confirmadas. Com relação à migração e ao trabalho forçado, novamente, é extremamente importante observar a exploração da vulnerabilidade dessas pessoas, que partem das suas casas com a promessa de uma vida melhor, mas acabam sendo vítimas de opressão, tendo seus documentos retidos e sendo até consideradas criminosas (PISCITELLI, 2008). De acordo com Anderson (2014), a solução para esse problema não está na melhoria das condições laborais, mas sim na abolição da relação entre o tráfico de pessoas e o trabalho, que deve focar no caráter exploratório, ou seja, nas relações de dominação que compõem a ligação entre o empregador e o empregado. Para ela, a dicotomia entre trabalho voluntário (regulamentado e por prazer) e trabalho não voluntário ou involuntário (situação de miséria ou semelhante à escravidão) gera um problema que as feministas, no caso da prostituição, enfrentam, que é a distinção entre mão-de-obra forçada e consensual, levando a questionar o que é "trabalho forçado" e o que é trabalho livre" (ANDERSON, 2014).

Finalmente, o último tipo de exploração que aparece no Protocolo de Palermo é a remoção de órgãos. Assim como a prostituição e o trabalho escravo, o tráfico ligado à remoção de órgãos demonstra o caráter comercial com o qual é tratado o ser humano. É no crime organizado que o mercado de órgãos humanos tem a sua maior expressividade, envolvendo uma ampla rede humana e tecnológica que privilegia quem pode pagar mais (ÁVILA et al., 2008).

Segundo Scheper-Hughes (200o), o mercado de transplante de órgãos que ocorre hoje em um espaço transnacional, envolvendo cirurgiões, pacientes, doadores de órgãos, receptores, corretores e intermediários, é responsável por "reconceituar" o corpo humano como parte uns dos outros, já que necessidade de um órgão pode significar a vida ou a morte de outra pessoa. Dentro dessa perspectiva, são levantados vários dilemas éticos, sociais e médicos a respeito da comercialização de órgãos humanos e abusos dos direitos humanos, que visa suprir um mercado global emergente. (SCHEPER-HUGHES, 2000). Como explica Caldeira; Sanchez (2015): 
Perigosa, autêntica e ilícita é essa mercantilização de órgãos e tecidos humanos por trazer em seu bojo a possibilidade de manipulação financeira do campo da alocação de órgãos, estabelecimento de uma "tabela de preços" por órgão ou tecido, classificação do doador confirme a possível duração de sua vida, introdução de incentivos financeiros para a doação e transformação das guerras num proveitoso negócio, pois pela grande quantidade de cadáveres haverá grande quantidade de órgãos (CALDEIRA; SANCHEZ, 2015, p.12).

Da mesma forma que acontece com os outros tipos de exploração, também é observada, no mercado de órgãos, a saída de órgãos dos países menos desenvolvidos para os mais desenvolvidos. Na Índia, por exemplo, o comércio ilegal de rins é controlado por proprietários de hospitais que atendem a pacientes estrangeiros e nacionais ricos que esperam um doador vivo. Esses doadores, geralmente, são pessoas pobres, que vendem seus rins e assim os médicos lucram com as vendas (SCHEPER-HUGHES, 2000).

Considerando, portanto, todas as formas de exploração que compõem a definição do tráfico de pessoas e do contrabando de migrantes no cenário internacional, tanto as causas como as consequências são consideradas graves violações dos direitos humanos. A maioria dessas violações está ligada à dignidade física e pessoal do indivíduo, o direito à liberdade pessoal e à segurança e o princípio da não discriminação. Uma vez que essas violações cobrem uma ampla gama na esfera social e estão ligadas a diferentes tipos de atividades (nomeadamente o recrutamento, o transporte e a exploração), o enfrentamento ao tráfico de pessoas deve implicar em uma abordagem multidimensional que tenha na proteção às vítimas a sua posição central (RIJKEN, 2009, p.215). É sob essa perspectiva, que o conceito de segurança humana está calcado, tendo como principal pressuposto a segurança da vida humana como será explorado a seguir.

\section{O QUADRO CONCEITUAL DA SEGURANÇA HUMANA}

Em linhas gerais, a disciplina de Relações Internacionais ganhou força a partir dos debates acerca da proteção dos Estados contra as ameaças internas e externas que surgiram após os conflitos da Segunda Guerra Mundial. Como o propósito inicial era conter a guerra, a segurança era vista a partir da lógica estatal, sendo o Estado o principal provedor da segurança para os seus cidadãos. Atrelada a essa lógica, as ideias de soberania, legitimidade, política e autoridade passaram a fazer parte do conceito de segurança internacional, nas relações internacionais (BUZAN, HANSEN, 2012, p.34). Nas palavras de Buzan e Hansen (2012):

Seja na forma de "segurança nacional" ou, mais tarde, como a "segurança internacional" tradicionalista, a nação ou o Estado era o objeto de referência analítico e normativo. "Segurança internacional" não dizia respeito à substituição da segurança do Estado pela segurança da humanidade, do indivíduo ou de minorias dentro ou por meio de fronteiras estatais. Assegurar o Estado era visto 
instrumentalmente como a melhor maneira de proteger outros objetos de referência (BUZAN, HANSEN, 2012, p.37).

Um dos grandes problemas do conceito de segurança estadocêntrico (focado no Estado) é que ele somente considera ameaças àquelas que ultrapassam as fronteiras nacionais. Todavia, as preocupações que hoje afligem as sociedades não são somente os conflitos estatais. A globalização, por exemplo, tem ampliado as inseguranças e as incertezas e, perante o conceito tradicional de segurança estatal, deixado de abarcar essas "novas" dimensões, sejam elas acadêmicas, políticas ou sociais (AMARO, 2008).

O tema da segurança humana começou a aparecer justamente após a Guerra Fria, na globalização. A primeira ideia sobre seu conceito apareceu de maneira mais efetiva em 1994, em um relatório publicado pelo Programa das Nações Unidas para o Desenvolvimento - PNUD, que em meio às críticas ao modelo tradicional, procurou atrelar a segurança à noção de desenvolvimento e direitos humanos (NOBRE, 2016). Segundo o relatório:

O conceito de segurança há muito tempo foi interpretado de forma restrita: como segurança do território de agressão externa, ou como proteção de interesses nacionais em política externa ou como segurança global da ameaça do holocausto nuclear. Foi relacionado mais às nações do que as pessoas esqueceram as preocupações legítimas das pessoas comuns que buscavam segurança em suas vidas diárias. Para muitos a segurança simbolizava a proteção da ameaça de doenças, fome, desemprego, crime, conflito social, repressão política e riscos ambientais. Com as sombras escuras da Guerra Fria recuando, pode-se ver que muitos conflitos estão dentro das nações e não entre nações (PNUD, 1994, p.5).

Assim sendo, o conceito de segurança humana desenvolvido pelo relatório do PNUD ampliou o conceito de segurança focado no Estado para outras dimensões: econômica, que exige a garantia de uma renda básica ou trabalho produtivo e remunerado; alimentar, que diz respeito ao acesso a todas as pessoas à alimentação; política, que se refere ao respeito e à proteção dos direitos humanos contra qualquer tipo de repressão; ambiental, que está ligada à manutenção do ambiente físico saudável, livre de poluição, desmatamento, desertificação, entre outros; comunitária, que visa a integridade da diversidade cultural; individual, que visa a segurança contra as diversas formas de violência; e, por fim, a dimensão da saúde, que está ligada ao acesso tanto aos cuidados e acesso à saúde como o combate a ameaças (NOBRE, 2016).

Essencialmente, o conceito de segurança humana estabelecida pelo PNUD fornece uma compreensão multidimensional do conceito de segurança que diz respeito ao "freedom from fear and freedom from want" (liberdade do medo e liberdade do querer). Essas duas liberdades estão focadas na proteção das pessoas contra as vulnerabilidades resultantes do subdesenvolvimento (liberdade do querer), e da violência física decorrente das guerras e dos conflitos civis (liberdade do medo) (OLIVEIRA, 2011).

Tendo em vista esse foco, a segurança humana também dá ênfase à universalidade, ou seja, a preocupação com a segurança humana é universal e relevante para todas as pessoas em todos os 
lugares, sejam ricos ou pobres. Os componentes da segurança humana também são interdependentes (tanto militares como não militares, as fontes de segurança se sobrepõem); e, por ser interdependente, é mais fácil garantir a segurança humana por meio da prevenção, e não pela intervenção. Assim, a segurança humana não é somente uma preocupação com as armas, mas sim uma preocupação com a vida e com a dignidade do indivíduo (ALKIRE, 2003). Isso é o que Kofi Annan, em seu Relatório às Nações Unidas em 2000 aborda:

Segurança humana em seu sentido mais amplo engloba muito mais do que a ausência de conflitos violentos. Ela engloba os direitos humanos, a boa governança, o acesso à educação e cuidados de saúde e assegura que cada indivíduo tenha oportunidades e escolhas para cumprir o seu próprio potencial. Cada passo nessa direção é também um passo para a redução da pobreza, crescimento econômico e prevenção de conflitos. Ausência de miséria, liberdade do medo e a liberdade das gerações futuras herdarão um ambiente saudável natural - estes são os blocos de construção inter-relacionados da segurança humana - e, portanto, nacional (ANNAN, 2002 apud ALKIRE, 2003, p.14).

De acordo com Tadjbakhsh (2005), academicamente, o conceito de segurança humana tem sido tratado levando em consideração três abordagens. Em primeiro, "aqueles para quem a segurança humana representa uma ideia atraente, mas que carece de rigor analítico”. Essa abordagem é defendida principalmente pelos críticos à segurança humana, os quais argumentam ser um conceito amplo e de difícil identificação das ameaças. Em segundo, há “aqueles que, ao aceitar o termo, insistem em limitá-lo a uma definição estrita”, que diz respeito, sobretudo, à diminuição da violência. E, por fim, “aqueles para quem a definição ampla do conceito de segurança humana é uma ferramenta essencial para a compreensão de crises contemporâneas”. Esse grupo acredita que a amplitude de dimensões que a segurança humana trata incentiva o debate em torno das relações de poder e exige que as preocupações de segurança humana se tornem prioridades de ação política (TADJBAKHSH, 2005).

Apesar dos críticos apontarem a amplitude de temas como um problema para a segurança humana, ela fornece um debate em torno de termos essenciais para as relações internacionais que permite o questionamento de normas de soberania, segurança coletiva e política de poder. Dessa forma, a amplitude de dimensões da segurança humana visa ampliar também a responsabilidade do Estado com os aspectos da proteção das fronteiras, em vista a incluir o fornecimento do bem-estar da população (TADJBAKHSH, 2005). Assim, como aponta Owen:

O Estado é um importante, embora não o único, provedor da segurança humana. É o estado [...] que tem não só a responsabilidade primordial de promover a segurança humana, mas também o potencial para abusar dos seus poderes relacionados, tanto em termos de como ele define ameaças e como ele responde a eles. A segurança humana e do Estado devem, portanto, trabalhar em simbiose (OWEN, 2008, p.449 apud NOBRE, 2016, p.41). 
Em suma, o que a segurança humana visa produzir com relação à perspectiva tradicional de segurança focada no Estado é a ampliação dos aspectos que são considerados ameaças. Segundo Newman, todas as abordagens da segurança humana concordam que o principal referente da segurança deve ser o indivíduo. A abordagem ampliada das ameaças fornece um "guarda-chuva" conceitual, com o objetivo de aproximar os aspectos "não-tradicionais" da segurança, como terrorismo, armas, drogas, HIV/AIDS e tráfico e contrabando, para dentro da agenda de segurança dos Estados (NEWMAN, 2010, p.80). A partir desse pressuposto, busca-se entender como a visão ampliada das ameaças pode facilitar o enfrentamento do tráfico e do contrabando pelos Estados.

\section{UM OLHAR PARA O TRÁFICO POR MEIO DA SEGURANÇA HUMANA}

Como exposto, olhar o problema do tráfico de pessoas e do contrabando de migrantes pelo olhar da segurança internacional pode não dar a atenção devida às vítimas. Em seu estudo sobre o tráfico sexual, Goodey (2004) chama a atenção para a necessidade de uma abordagem focada na “centralidade da vítima”. Para a autora, é preciso enfatizar os desejos das pessoas traficadas, cujas experiências estão no cerne do processo criminal. Sem a devida consideração dos desejos individuais e do olhar dessas pessoas sobre a sua situação, as respostas jurídicas ao tráfico de pessoas permanecem insuficientes. Por outro lado, um tratamento sensível e oportuno às vítimas de tráfico pode garantir medidas mais eficazes (GOODEY, 2004, p.42). Dado esse pressuposto, a segurança humana, a qual amplia as ameaças que deverão ser reconhecidas pelos Estados, aponta para o problema do tráfico também como uma ameaça, mas que deverá ser vista pela ótica do indivíduo. A abordagem da segurança humana propõe uma discussão focada essencialmente na diminuição do risco de exploração dos vulneráveis.

De acordo com Clark (2003), certas populações são mais vulneráveis e por isso são exploradas devido aos fatores econômicos, políticos e sociais. Esses fatores contribuem para um estado de elevada insegurança, que são aproveitados pelos traficantes ou contrabandistas na identificação das vítimas e, a partir disso, é que eles garantem o sucesso de sua atividade. A exploração da vulnerabilidade das pessoas é acordada pela Convenção de Palermo de 2000 como um dos meios ilícitos que são utilizados pelos criminosos como forma de exploração. Dados os processos que envolvem cada tipo de exploração, seja exploração sexual ou prostituição, trabalho forçado ou outras formas de escravidão e remoção de órgãos, identificar essas ameaças é essencial para combatê-las. Dentre os diversos fatores, Clark (2003) identifica pelo menos três áreas que geram a vulnerabilidade: A econômica, a do enraizamento do crime organizado e a sociocultural (CLARK, 2003). A partir da percepção dessas áreas como geradoras de vulnerabilidades, é possível identificar e enfrentar as ameaças de maneira mais assertiva. 
O fator econômico é muitas vezes o fator determinante no deslocamento de pessoas. Grande parte dos criminosos se aproveita da vulnerabilidade econômica e enganam as pessoas com "melhores oportunidades" de emprego e renda. O desemprego e a pobreza são, portanto, motivos que levam as pessoas a se deslocarem em busca de melhores condições de vida. É com esse pretexto que os traficantes se aproveitam para enganar as vítimas. Essa vulnerabilidade pode ser combatida por meio da segurança humana mediante a promoção de oportunidades de emprego e renda para a população. Segundo Vasconcelos e Bolzon (2008), a promoção da liberdade, nem que seja relativa ao trabalhador, e a promoção de "mecanismos regulatórios que garantam uma maior igualdade de tratamento e de oportunidades no acesso ao trabalho e ao emprego" podem ser positivos no enfrentamento do trabalho forçado (VASCONCELOS; BOLZON, 2008, p. 79). E, dessa forma, poderão diminuir essa prática.

A segunda área de vulnerabilidade é gerada pelo enraizamento do crime organizado. Ao ser incorporado ao escopo da Convenção da ONU de 2000 contra o crime organizado transnacional relativo à prevenção, repressão e punição, o tráfico e o contrabando muitas vezes reproduzem uma prática que é extremamente complexa e hierarquizada. Por isso, a necessidade imediata para o enfrentamento dessa vulnerabilidade é por meio da segurança promovida pelo Estado (PACÍFICO; LEITE, 2011). Peksen (2018) examina o papel da capacidade do Estado na diminuição e prevenção do aumento dos fluxos ilícitos do tráfico. Para o autor, a capacidade do Estado, dividida em eficácia burocrática e capacidade fiscal, é particularmente importante no que tange a avaliação da eficácia das políticas públicas de enfrentamento ao crime dentro e fora das suas fronteiras. A eficácia burocrática é vital, pois aumenta o controle interno. Já a capacidade fiscal pode reduzir os custos das iniciativas ligadas ao combate (PEKSEN, 2018). Todavia, é fundamental, nessa área, além de quebrar a demanda existente entre o crime organizado e o tráfico, diminuir as desigualdades sociais que causam esse problema (SANTOS, 2015).

Assim, a última área geradora de vulnerabilidades é a área sociocultural, que está diretamente ligada às outras duas. Essa área se refere à reprodução de práticas culturais que são por si só dominadoras. No Brasil, por exemplo, a colonização, a escravidão negra, a cultura patriarcal e o machismo, reproduzem uma lógica de dominação do gênero masculino sobre o feminino. Nesses casos, é necessária uma mudança cultural. Ou até mesmo a percepção de que essas práticas reproduzem uma lógica opressora de dominação (PACÍFICO; LEITE, 2011). Conforme analisado por Baptista (2021), o foco criminal do termo "tráfico de pessoas" dá pouca ênfase às desigualdades sociais que levam as pessoas a serem vítimas desse tipo de crime. Um dos indícios dessa pouca abordagem é justamente o pouco envolvimento sociocultural. Esse é sem dúvidas um desafio a ser enfrentado pela comunidade internacional na busca de ações coordenadas com o local que visem um maior aprendizado cultural (BAPTISTA, 2021).

De maneira geral, todas as áreas estão interligadas, em vista disso, é que o enfrentamento multidimensional proposto pela segurança humana pode fornecer uma fonte fundamental na 
proteção das liberdades fundamentais, que são a essência da vida humana. A proteção para a segurança humana significa proteger as pessoas contra as ameaças críticas (graves) e penetrantes (generalizadas) e também usar processos que construam as aspirações das pessoas, que visam criar um sistema econômico, político, social e cultural que dê às pessoas os elementos básicos para sua sobrevivência, subsistência e dignidade (NEWMAN, 2010). A segurança humana pode diminuir os riscos do tráfico ao ser utilizado pelos Estados como uma ferramenta que amplia o escopo das ameaças a fim de dar ênfase ao enfrentamento do tráfico e do contrabando pela ótica do indivíduo e não somente pela ótica do Estado. Ao identificar as ameaças, o Estado pode assim promover políticas de enfrentamento mais eficazes diminuindo os riscos do tráfico, por meio da diminuição das causas que geram as vulnerabilidades que são exploradas pelos criminosos e, dessa forma, diminuir a demanda profunda do crime organizado transnacional.

\section{CONSIDERAÇÕES FINAIS}

Diante do discutido, foi visto que, após a adoção da Convenção de Palermo, de 2000, o problema do tráfico e do contrabando de pessoas passou a ser tratado pela comunidade internacional como um processo ligado essencialmente ao crime organizado internacional, que é considerado uma ameaça à segurança do Estado. Nessa lógica, as pessoas exploradas, as violações dos direitos humanos e o tratamento das vítimas são negligenciados por não fazerem parte da perspectiva de segurança ligada ao tráfico e ao contrabando de pessoas (DIAS, 2015).

Para tanto, o objetivo desse artigo foi discutir o problema do tráfico e do contrabando de pessoas pela ótica do indivíduo que é explorado, utilizando o conceito de segurança humana como um "guarda-chuva" conceitual que visa, sobretudo, tratar esse problema como uma ameaça que vai além da ameaça à segurança estatal, como é reconhecido atualmente esse problema no cenário internacional. Foi proposto, portanto, um "novo olhar" para o tráfico. Uma abordagem de baixo para cima, que envolva as vítimas e os governos com a comunidade internacional.

O conceito multidimensional com o qual é composto o conceito de segurança humana propõe, para o enfrentamento do tráfico e do contrabando de pessoas, um olhar sobre as ameaças estruturais que geram as vulnerabilidades. Nesse caso, foram identificados três: a econômica, o enraizamento do crime organizado e a sociocultural. Assim, para minimizar os riscos do tráfico e terse um enfrentamento mais eficaz, o Estado deverá mitigar essas três vulnerabilidades para que, assim, possa minimizar as causas e as consequências desse problema. O que se verifica é necessidade de um enfrentamento multidimensional para um fenômeno que atinge múltiplas áreas da sociedade. Espera-se que esse artigo sirva como um guia na busca por uma solução mais satisfatória entre as partes envolvidas. 
*Artigo recebido em 29 de novembro de 2020, aprovado em 22 de março de 2021.

\section{REFERÊNCIAS}

AMARO, António. Segurança humana e proteção civil na sociedade do risco: a crise do modelo estatocêntrico na (s) segurança (s). Territorium, Revista da Associação Portuguesa de Riscos, Prevenção e Segurança, v. 15, p. 83-94, 2008.

ANDERSON, Bridget. Trafficking. In FIDDIAN-QASMIYEH, Elena et al. (Ed.). The Oxford handbook of refugee and forced migration studies. OUP Oxford, p. 355-366, 2014.

ALKIRE, Sabina, 'Concepts of Human Security'. In: Lincoln C. Chen, Sakiko FukudaParr \& Ellen Seidensticker, eds, Human Security in a Global World. Cambridge, MA: Harvard University Press p. 15-40, 2003.

ÁVILA, Gustavo Noronha de et al. Comércio de órgãos humanos: até onde vai a autonomia do indivíduo? Direito \& Justiça, v. 34, n. 1, 2008.

BAPTISTA, Vinicius Ferreira. Três esquemas analíticos para analisar o tráfico internacional de pessoas: em busca de uma concepção política da violência. Research, Society and Development, v. 10, n. 1, p. e42110111993-e42110111993, 2021.

BHABHA, Jacqueline; ZARD, Monette. Tráfico o trata? Revista de Migrações Forçadas, $\mathrm{N}^{\circ}$ 24, agosto 2006.

BRASIL. Decreto no 5.948, de 26 de outubro de 2006. Política Nacional de Enfrentamento ao Tráfico de Pessoas e institui Grupo de Trabalho Interministerial com o objetivo de elaborar proposta do Plano Nacional de Enfrentamento ao Tráfico de Pessoas - PNETP. 2006.

BUZAN, Barry; HANSEN, Lene. A evolução dos estudos de segurança internacional. Tradução Flávio Lira. São Paulo: Ed. da UNESP, 2012.

CALDEIRA, Gabriela Guilherme; SANCHES, Cláudio José Palma. Transplantes de órgãos e tecidos. ETIC-ENCONTRO DE INICIAÇÃO CIENTÍFICA, v. 10, n. 10, 2015.

CAMPOS, Bárbara Pincowsca Cardoso. O tráfico de pessoas a luz da normativa internacional de proteção dos direitos humanos. Revista do Instituto Brasileiro de Direitos Humanos, v. 7, n. 7, 2007.

CLARK, Michele Anne. Trafficking in persons: An issue of human security. Journal of Human Development, v. 4, n. 2, p. 247-263, 2003.

COSTA, De Leon Petta Gomes da. Tráfico de seres humanos como ameaça na política internacional: um caso de desterritorialização?. São Paulo. Tese de Doutorado. Universidade de São Paulo, 2012.

DIAS, Guilherme Mansur. Notas sobre as negociações da "Convenção do crime" e dos Protocolos Adicionais sobre Tráfico de Pessoas e Contrabando de Migrantes. REMHU: Revista Interdisciplinar da Mobilidade Humana, v. 23, n. 45, p. 215-234, 2015. 
GOODEY, Jo. Sex trafficking in women from central and east European countries: Promoting a 'victim-centred'and 'woman-centred'approach to criminal justice intervention. Feminist review, v. 76, n. 1, p. 26-45, 2004.

KEMPADOO, Kamala. Mudando o debate sobre o tráfico de mulheres. Cadernos Pagu, v. 25, p. $55-78,2005$.

LARA, Ana María. Perspectivas de seguridad de las migraciones internacionales: una propuesta para enfrentarlas. Revista de relaciones internacionales, estrategia y seguridad, v. 3, n. 1, 2008.

NEWMAN, Edward. Critical human security studies. Review of International Studies, v. 36, n. 1, p. 77-94, 2010.

NOBRE, Fábio Rodrigo Ferreira. Alto El Fuego: a mensuração e a eficácia da segurança humana na construção da paz na Colômbia e no Peru. Recife. Tese de doutorado. Universidade de Pernambuco, 2016.

OLIVEIRA, Ariana Bazzano de. Segurança humana: avanços e desafios na política internacional. São Paulo. Dissertação de Mestrado. Universidade Estadual de Campinas, 2011.

ORGANIZAÇÃO DAS NAÇÕES UNIDAS. (2000). Penal matters: 12.a. Protocol to prevent, suppress and punish trafficking in persons, especially women and children, supplementing the United Nations Convention against Transnational Organized Crime. Disponível em: <https://treaties.un.org/doc/publication/mtdsg/volume\%20ii/chapter\%20xviii/xviii-12-a.en.pdf> Acesso: 28 de fevereiro de 2020. Acesso em 29 de maio de 2021.

PACÍFICO, Andrea Pacheco; LEITE, Junne Maria Duarte Barbosa; SOUTINHO, Márcia Wanderley. As causas do tráfico e/ou contrabando de nordestinas para Europa. Revista Interdisciplinar da Mobilidade Humana, v. 16, n. 31, 2010.

PACÍFICO, Andre Pacheco; LEITE, Junne Maria Duarte Barbosa. Mecanismos institucionais de prevenção e combate ao tráfico de pessoas no Brasil. Revista Interdisciplinar da Mobilidade Humana, v. 19, n. 37, 2011.

PISCITELLI, Adriana. Entre as "máfias" e a "ajuda": a construção de conhecimento sobre tráfico de pessoas. Cadernos Pagu, n. 31, p. 29-63, 2008.

PIRES, Aline Silva; GALVÃO, Denise Lúcia Camatari. Tráfico de pessoas e tráfico ilícito de migrantes. Os direitos individuais das pessoas em mobilidade. Revista Interdisciplinar da Mobilidade Humana, v. 16, n. 31, 2010.

PINTO, Ana Luísa Pombo Diogo. Tráfico (des) humano. Porto. Dissertação de Mestrado. Universidade Lusíada Do Porto, 2017.

PNUD. Human Development Repport. Published for the United Nations. Development Programme. (UNDP). New York. Oxford. Oxford University Press, 1994.

RIJKEN, Conny. A human rights based approach to trafficking in human beings. Security and Human Rights, v. 20, n. 3, p. 212-222, 2009.

SANTOS, Alessandra Rufino. Tráfico humano e contrabando de migrantes em regiões de fronteiras. Textos e Debates, v. 2, n. 27, 2015. 
SALES, Lília Maia de Morais; ALENCAR, Emanuela Cardoso Onofre de. Tráfico de seres humanos, Migração, Contrabando de migrantes, Turismo sexual e Prostituição: algumas diferenciações. Novos Estudos Jurídicos, v. 13, n. 1, p. 29-42, 2008.

SCHEPER-HUGHES, Nancy et al. The global traffic in human organs. Current Anthropology, v. 41, n. 2, p. 191-224, 2000.

SCACCHETTI, Daniela Muscari. O tráfico de pessoas e o protocolo de Palermo sob a ótica de direitos humanos. Revista Internacional de Direito e Cidadania, n. 11, p. 25-38, 2011.

TADJBAKHSH, SHAHRBANOU. Human Security: Concepts and Implications with an Application to Post-Intervention Challenges in Afghanistan. Les Etudes du CERI, No. 117-118. Paris: Sciences Po, 2005.

UNITED NATIONS OFFICE ON DRUGS AND CRIME. (2002). Convenção das Nações Unidas contra o crime organizado transnacional. Disponível em: < http://www.planalto.gov.br/ccivil_03/_ato2004-2006/2004/decreto/d5015.htm> Acesso em: 22 de junho de 2021.

UNITED NATIONS OFFICE ON DRUGS AND CRIME. (2017). Relatório mundial de Drogas. Disponível em: https://www.unodc.org/wdr2017/field/Booklet_2_HEALTH.pdf Acesso em: 28 de fevereiro de 2020. Acesso em 29 de maio de 2021.

UNITED NATIONS OFFICE ON DRUGS AND CRIME. (2020). Relatório Global sobre Tráfico de Pessoas. Disponível em: <https://www.unodc.org/documents/data-andanalysis/tip/2021/GLOTiP_2020_15jan_web.pdf> Acesso em: 28 de fevereiro de 2020. Acesso em 29 de maio de 2021.

VASCONCELOS, Marcia; BOLZON, Andréa. Trabalho forçado, tráfico de pessoas e gênero: algumas reflexões. Cad. Pagu, São Paulo, n. 31, p. 65-87, 2008. Acesso em 29 de maio de 2021.

VENSON, Ana Maria Marcon; PEDRO, Joana Maria. Human trafficking: a historical approach to the concept. Revista Brasileira de História, v. 33, n. 65, p. 61-83, 2013. Acesso em 29 de maio de 2021. 